\title{
El giro oscurantista en antropología. De la zoomanía al animalismo occidentales*
}

\author{
Jean-Pierre Digard ${ }^{* *}$ \\ Traducción del francés al español \\ de Luis Alfonso Palau Castaño \\ DOl: 10.22395/csye.v6n11a14
}

La materia de este artículo fue objeto de una comunicación oral en el coloquio internacional organizado en el Colegio de Francia, del 22 al 24 de junio de 2011, por Frédéric Keck y Noëlie Vialles sobre el tema: «¿Un "giro animaliste" en antropología?». Habiéndose quedado a la espera de una eventual publicación en las actas de ese coloquio, he preferido, en razón de la gravedad y de la actualidad del tema, no esperar más tiempo y aprovechar la hospitalidad que la redacción de L'Homme me ha ofrecido amablemente.

Imaginemos un viajero que desembarca de otro planeta, o de otra época, en la Europa o en la América del Norte contemporáneas: no podría dejar de sorprenderse, entre otros motivos de sorpresa, por el lugar y el estatus (por lo menos paradójico) que los occidentales les asignamos a los animales. Mientras que entregamos a los unos -bovinos, porcinos, aves- a una explotación despiadada, cada vez más masiva, sobreprotegemos y maternizamos a los otros -los "animales de compañía"- casi como a nuestros propios hijos. Pero hay más: algunos de nosotros militan a favor de los animales como otros a favor de los humanos; ¿acaso no vimos en París en el otoño de 2010, paralelo al movimiento de protesta por la reforma de las pensiones, a otros manifestantes reclamar jaulas más espaciosas para los conejos? Es lo que, siguiendo a Ernest Hemingway (1938 [1932]: 19), llamaría el fenómeno "animalitario". Además, otros, entre los cuales hay científicos con casa propia, discuten doctamente sobre el animalismo como de una noción evidente, o de una "ontología" entre las otras.

El uso variable que se hace de la palabra "animalismo" necesita aquí una puntualización. En efecto, ora designa la atención que las ciencias del hombre

Tomado de Jean-Pierre Digard, "Le tournant obscurantiste en anthropologie», L'Homme [En ligne], 203-204, 2012, mis en ligne le 03 décembre 2014, consulté le 24 février 2017. URL: http://homme.revues.org/23292; DOI: 10.4000/lhomme.23292. Traducción de Luis Alfonso Paláu Castaño, Medellín, febrero 26 de 2017. Nota del traductor.

** Director de investigación en el CNRS y profesor de la EHESS (París) y la Universidad de Provence (Aix). Es autor, entre otros libros, de Les Français et leurs animaux. Ethnologie d'un phénomène de société (Fayard, 1999) y Une histoire du cheval. Art, techniques, sociétés (Actes Sud, 2004). Nota del editor. 
y de la sociedad han puesto en los animales. En este sentido, el animalismo no data de hoy, así como lo testimonian disciplinas bien establecidas como la arqueozoología (Chaix \& Méniel 2001 [1996]), las etnociencias entre las cuales la etnozoología (Pujol \& Carbone 1990) y la etnozootécnica (Digard 2010), la etnología de las sociedades de pastores nómadas (Équipe Écologie et anthropologie des sociétés pastorales, ed. 1979) como también la antropología de la domesticación animal (Digard 2009a [1990]). Ora, la palabra "animalismo" designa el desplazamiento -nuevo, como vamos a verlo- del centro de gravedad social y cultural del hombre hacia el animal, en una especie de pendiente intelectual del activismo animalitario. Es en este segundo sentido, y solamente en él, que aquí usaremos el término "animalismo".

El cuadro contrastado que acabamos de esbozar resulta a la vez de evoluciones de sociedad y de evoluciones intelectuales relativamente recientes.

\section{Evoluciones de sociedad}

\section{La "modernización" de la ganadería}

En un contexto dominado por la necesidad de reconstruir la economía destruida por la Segunda Guerra Mundial, la ganadería tradicional, familiar y polivalente de la Francia de los años 1950 se ha concentrado poco a poco (los ganaderos representan en la actualidad menos del 1 \% de la población francesa), intensificado (con la multiplicación del levante "fuera del suelo" y / o "en batería") y especializado (con formación de "sub-sectores" distintos, bovinos de carne/bovinos de leche; pollos de carne/gallinas ponedoras, etc.).

Los cambios que, por lo demás, se hicieron en el modo de vida de los franceses no han hecho sino amplificar esta evolución; mientras que la población pasaba de 49 millones luego de la guerra a 65 millones actualmente, el consumo de carne progresaba de $50 \mathrm{~kg}$ a cerca de $100 \mathrm{~kg} / \mathrm{persona} /$ año entre 1950 y 1980, fecha en la que comenzó a regresar hasta los $90 \mathrm{~kg}$ actuales, lo que da, todas las cuentas hechas, una duplicación del consumo total de carne en Francia desde 1950.

Todos estos cambios han afectado evidentemente las relaciones hombres / animales de crianza, relaciones que se han vuelto más impersonales al punto que a veces entrañan estrés, tanto para los criadores como para los animales, sometidos los unos como los otros a la presión productivista (Porcher 2002).

La expansión y el cambio de naturaleza del fenómeno "animales de compañía" 
Las cifras siguen siendo en Francia: el número de los animales de compañía casi se ha duplicado en treinta años -en la actualidad son alrededor de 60 millones, entre los cuales 11 millones de gatos y 8 millones de perros-como aumentó el número de los hogares (53 \%) que los poseen. Lo que ha cambiado también y sobre todo es su estatus cultural (Digard 2005 [1999]): los animales de compañía hacen parte de ahora en delante de la familia donde son tratados como hijos, que le sirven incluso a veces a personas aisladas como sustitutos de sus hijos o de cónyuges. Pero, lejos de estar investidos de una función únicamente catártica, de remedio contra la soledad, hacen, por el contrario, parte, con la casa individual y el jardín, de una especie de kit de felicidad perfecta de la familia francesa media. Cada vez más antropomorfizados, son objeto de todas las atenciones: nada es demasiado bonito ni caro para ellos, para su alimento, sus cuidados, su salud (de acá la proliferación de clínicas veterinarias en las ciudades).

De aquí en adelante generalizado en una población cada vez más urbanizada o "rurbanizada" -en todo caso ahora separada por completo de sus lejanas raíces campesinas- el modelo dominante del animal de compañía tiende, además, a englobar otras categorías de animales: diversos animales domésticos (hurones, conejos y marranos enanos), comensales (ratas, ratones) o exóticos (<reptiles> varanos, diversas serpientes, <arañas > migalas) que una moda reciente promovió al rango de "nac" (nuevos animales de compañía); el caballo, "animal intermediario", que desde que abandonó la esfera de lo utilitario por la de ocio, se volvió el animal preferido de los franceses detrás del perro y el gato, y ve cómo su estatuto tiende hacia el de animal de compañía (Digard 2007 [2004] : 195-200); y finalmente la fauna salvaje, a propósito de la cual se multiplican los documentales teledifundidos, más o menos lacrimosos, que presentan lobos, osos, grandes felinos o tiburones como apacibles e inofensivas creaturas a las que el hombre, diabolizado, no ha dejado de perseguir sin razón... mientras que sería seguramente más exacto y más aclarador insistir en las "cascadas tróficas" que la disminución de las poblaciones de esos grandes depredadores no deja de provocar (Estes et al. 2011).

En el sistema de relaciones de los franceses con los animales, la fauna salvaje (que, por lo demás, es cada vez menos "salvaje", pues de ahora en adelante está administrada, regulada, reconstituida, protegida, sembrada o se le da forraje...) ocupa una posición simétrica e inversa de la de los animales de compañía; simétrica porque las dos categorías de animales gozan 
del mismo estatus de cumbre y comparten la misma "inutilidad" ; posición inversa puesto que, mientras que los animales de compañía representan el colmo de la antropización y son apreciados precisamente por esta proximidad, los animales salvajes deben, por el contrario, su aura al sentimiento (en parte ilusorio como hemos visto) de que están "indemnes" de toda acción humana, que no están "contaminados" por el hombre, al ser percibido este último por el maniqueísmo ecologista moderno como la encarnación de la maleficencia.

Ahondamiento de la distancia entre animales de renta y animales de compañía

La conjunción de los fenómenos evocados en las dos secciones precedentes revela pues una jerarquización muy clara entre una plebe animal, los animales de renta, y una élite animal, los animales de compañía. Mientras que estos últimos están omnipresentes y manifiestamente supervalorados, los primeros aparecen tanto más marginalizados, disimulados, menospreciados como intensamente explotados. La diferencia se ha ampliado por una tendencia histórica, constante desde finales de la Edad Media, a la miniaturización de los animales de compañía y a la mastodontización de los animales de renta.

Más aún: entre los animales de renta y los animales de compañía, entre la ostracización de los primeros y la exposición ostentatoria de los segundos, la distancia no deja de crecer, bajo la doble influencia de la concentración, de la especialización y de la industrialización creciente de las ganaderías vacunas lechera y de dehesa, así como de la mercantilización excesiva del fenómeno animales de compañía. Estos representan en efecto un presupuesto considerable ${ }^{2}$ y una cifra de negocios anual proporcional cercana a los icuatro mil millones de euros! Frente a esta cesta, la industria agroalimenticia duda cada vez menos en hacer vibrar la cuerda sentimental en sus campañas publicitarias, contribuyendo así a la antropomorfización desmesurada de los animales de compañía ${ }^{3}$.

1 Por definición, los animales salvajes no son objeto de ninguna explotación con fines utilitarios, industriales o comerciales; los propios cazadores no cuentan para nada con su presa para nutrirse.

2 En Francia, en el presupuesto familiar promedio, la parte de los animales de compañía, especialmente para su alimentación, es igual a la de los transportes en común, avión y barco comprendidos.

3 Con su cortejo de manifestaciones como, por ejemplo, el perfume para perro Ô my dog o los desfiles de moda canina de la estilista Marie Poirier. 


\section{La radicalización de la movida animalitaria}

El mundo de la protección animal constituye una nebulosa compleja de alrededor de 280 asociaciones, enla sola Francia (Burgat 1997b), que va desde los "Amigos del cangrejo grande de mar" hasta la vieja y (no siempre) respetable Sociedad Protectora de Animales, fundada a mediados del siglo XIX, a las que se añaden ahora las bien prósperas y activísimas (especialmente en el dominio jurídico) Fundación Brigitte Bardot o la Liga de los derechos del animal.

El cambio compromete aquí cuatro fenómenos concomitantes. En primer lugar, al deslizamiento progresivo de la noción de "protección animal", concebida como un deber de compasión del hombre, hacia la noción de "derechos del animal", e incluso (para los militantes más radicales) a la de "liberación animal", a nombre del "anti-especismo" o, en espaninglis corriente, "antispecisme". Estas nociones, popularizadas por Peter Singer (1993 [1975]), provocan de entrada algunos comentarios. El anti-especismo se define como la oposición al "espejismo", es decir a la actitud que consiste en negarles a las otras especies lo que se reivindica para la propia. Según este principio, cualquiera que se oponga a la pena de muerte para los humanos debe lógicamente negarse igualmente a la matanza de los animales de carnicería, la cacería, la pesca, la eliminación de los depredadores, de los roedores, y de los insectos dañinos, de los parásitos, etc. La noción de especismo está calcada sobre la de racismo para la especie humana. Sin embargo, las dos no tienen nada de comparable; mientras que el racismo deriva su carácter monstruoso de la no-existencia de las razas en el hombre, el espejismo es absurdo puesto que las especies sí existen, tienen un contenido biológico que erige entre ellas barreras genéticas generalmente infranqueables (excepto en raros casos de hibridación). El anti-especismo no es pues nada distinto a una elección filosófica que busca justificarse a posteriori por medio de argumentos científicos mal comprendidos o voluntariamente falsificados: el hombre y el chimpancé son presentados como casi semejantes en virtud de su $98 \%$ de genes en común (olvidando el $2 \%$ de genes que no son comunes, los "genesclave" o "genes conmutador", que constituyen toda la diferencia); palabra "animal" siempre empleada en singular para colocarlo mejor en simetría con el hombre (a pesar de la existencia de una decena de millones de especies animales, con las que es inconcebible mantener relaciones idénticas); etc.

Segundo aspecto de la radicalización: la causa animalitaria es defendida ahora activamente, sostenida, empujada ante las autoridades nacionales e 
internacionales por un lobbying a la anglosajona, extremadamente poderoso y organizado así sobre el terreno, como por grupúsculos hiperactivos, algunos muy violentos, hasta el punto de ser clasificados en los Estados Unidos como la segunda amenaza terrorista luego del activismo islamista ${ }^{4}$.

Tercero, las reivindicaciones animalitarias escalan en una espiral del siempre más que los arrastra inexorablemente hacia derivas extremistas. Es así como, por ejemplo, se ha podido ver en los "Encuentros Animal y Sociedad" organizados en la primavera de 2008 por el Ministerio de Agricultura, cómo se metamorfoseaba la exigencia de "bienestar animal" (Burgat \& Dantzer 2001) primero en exigencia de introducción en el Código Civil, para los animales en tanto que "seres sensibles", de una tercera categoría intermediaria entre las personas y los bienes, con las consecuencias jurídicas y económicas que ello conlleva, hasta llegar a la reivindicación de "derechos del animal", a nombre de la "Declaración universal de los derechos del animal", parodia de la Declaración de los derechos del hombre, autoproclamada en 1978. De manera más general, es la misma lógica que empuja a los "vegetarianos" (opuestos al consumo de carne) a volverse "vegetalianos" (opuestos al consumo de todo producto de origen animal), y posteriormente "veganos" (opuestos a toda crianza y utilización de animales), hasta la deep ecology que se preocupan por la defensa de los árboles, de los frutos y de las legumbres a nombre del anti-especismo. Es, además, y siempre la misma lógica la que finalmente conduce al anti-especismo a acusar y a diabolizar al hombre, a mudarse así en un especismo anti-humano, por tanto en anti-humanismo.

Cuarto y final, habría mucho que decir de la invasiva consigna de "bienestar animal", traducción abusiva del inglés welfare que sería más exacto presentar como "buen trato" (Picard, Porter \& Signoret 1994). Lejos de ser la expresión de un "justo medio"5 no es por el contrario más que un señuelo subjetivo e hipócrita (cf. Bourdon 2003; Digard 2009b: 102-105; Porcher 2004 et 2011: 109-117). En efecto, si se quiere adoptar el punto de vista de los animales, sus criterios se revelan muy difíciles de establecer. Si es el punto de vista de los ganaderos el que se escoge, uno no puede dejar de preguntarse cuál de ellos se mostraría suficientemente incompetente o bastante estúpido como para entregar (excepto accidente) en la feria de ganado animales que no estuvieran "en debida forma". Para algunos tecnócratas internacionales, el "bien estar animal" no es sino un medio cínico de imponer normas de

\footnotetext{
4 Cfr. la novela policíaca muy documentada de Jean-Claude Rufin (2007) y la investigación sociológica de Isacco Turina (2010).

5 Como querría hacerlo creer Jean-Baptiste Jeangène Vilmer (2008).
} 
producción que se sabe por adelantado que no están al alcance de los más desprotegidos. Finalmente, ¿qué se puede pensar de esos agrónomos o zootecnistas sin conciencia que trabajan en la elaboración (para el ganado europeo) de criterios de "bienestar" (saciedad, sueño, comodidad...) que son desconocidos por una buena tercera parte de la humanidad?

\section{Evoluciones intelectuales}

\section{Una Ienta oscilación de la jerarquía de valores desde el siglo XVIII}

Estas evoluciones intervienen en un contexto marcado por una modificación lenta pero continua, desde hace muchos siglos, de las ideas y de las sensibilidades concernientes a la naturaleza y a los animales, en particular por la difusión del ecologismo (que no debemos confundir con la ecología) que luego de haber encontrado sus raíces en el romanticismo del siglo XIX, actor del cuestionamiento del lugar preeminente dado al Hombre en provecho de la Naturaleza, se dice que podría volverse la ideología dominante del siglo XXI... En efecto, en la prolongación de las sensibilidades románticas, el ecologismo reposa en una visión maniquea del mundo, caracterizada por una percepción pesimista del hombre en tanto que ser esencialmente dañino, y por una visión angélica e idealizada de la naturaleza, reputada fundamentalmente como bella y buena.

Aparecidas en las pisadas de la Revolución francesa, las ideas de compasión con los animales, y de su protección, se instalan también en las prácticas a partir de mediados del siglo XIX, con la fundación de la SPA en 1845, y la adopción en 1850 de la ley Grammont contra los maltratos a los animales domésticos en público (Agulhon 1981; Pelosse 1981-1982). Esas ideas conocieron un aumento en su difusión a fines del siglo XIX debido a la convergencia del movimiento proteccionista y del movimiento feminista, dado que este último consideraba a las mujeres y a los animales como igualmente víctimas de los hombres ${ }^{6}$.

¿Cómo no anotar también, como telón de fondo, la lenta erosión del humanismo de la Ilustración bajo la presión conjugada del capitalismo triunfante y de las ideologías postmodernistas? Y como reverso de la idealización de la naturaleza y de la compasión por los animales, aparece la diabolización del hombre o, en todo caso, su menosprecio se acentúa con la desaparición de los grandes "-ismos" (exceptuando el cinismo), con la

\footnotetext{
Cf. Adams (1995) et Pierre (1997) que distingue y opone por otra parte "protección de utilidad», para la educación pública, y «protección de sensibilidad», portadora de misantropía.
} 
entrada de Occidente en la "Posmodernidad" (Lyotard 1979) o la "sobremodernidad" (Balandier 2005), caracterizada por el hiper-relativismo para el que "todo se vale", por la "vida líquida" donde todo es desechable (Bauman 2006), por el cambio por el cambio, por el enturbiamiento generalizado de las diferencias (entre los sexos, entre las generaciones, entre la libertad y el individualismo...), etc.

Tal es el entorno ideológico general en el que aparecen, en las ciencias del hombre y de la sociedad, así como en algunos dominios contiguos, muchos enfoques nuevos de las cuestiones sobre las relaciones hombres/animales.

\section{Aceleraciones y amplificaciones contemporáneas}

Una imponente bibliografía, sobre todo en inglés, testimonia la amplitud y el vigor de estas prolongaciones ${ }^{7}$. Muchos campos o corrientes pueden ser distinguidos.

Primeros cronológicamente, puesto que se reclaman del utilitarismo de Jeremy Bentham (1748-1832); los filósofos animalistas han erigido en vulgata la denuncia de la teoría del "animal-máquina", que equivocadamente atribuyen a Descartes confundido con Malebranche (Cottingham, 2009). Que confiesen o no su "impotencia para definir algo que sea propio del hombre" (Fontenay 1998: 13); su punto en común es dedicarse a minimizar o a borrar toda diferencia entre el hombre (human animal) y los animales (non human animals $)^{8}$. Es el tipo de preguntas que se hacen sin reír esos filósofos que adolecen de paradigma: "¿Es libre mi perro?" (Dortier 2008). La corriente filosófica animalista se inscribe, a su vez, en una más amplia, la filosofía ecologista que considera que "ya no podemos separar lo que tiene que ver con las acciones humanas y lo que es del orden de las fuerzas naturales; por esto la necesidad de una moral no antropocentrada, que promueva la naturaleza al rango de sujeto por respetar" (Dalsuet 2010); profesión de fe representativa de lo que se podría calificar de "romanticismo postmodernista". Siempre el ruido de esta corriente tiende a tapar las raras voces discordantes como las de Luc Ferry (1992), de Jean-Marie Meyer \& Patrice de Plunkett (2008), de Florence Eibl (2010) e incluso, a pesar de su envergadura y su alcance, la de Francis Wolff (2010).

\footnotetext{
7 Además de las referencias que da nuestra bibliografía, cfr. las numerosísimas repertoriadas por Chartrand \& Duhaime (2002).

8 Cfr. bajo formas y en diversos grados Chapouthier (1990); Burgat (1997); Larrère \& Larrère (1997); Fontenay (1998); Jeangène Vilmer (2008).
} 
En el surco de la filosofía animalista de la que saca su justificación intelectual, el militantismo animalitario lucha por otro tratamiento para los animales (Digard 2009b), teniendo, sin embargo, como lo hemos visto, una diferencia de grado entre, por una parte, una vía clásica que considera los animales como objetos de derecho con respecto a los cuales el hombre tendría deberes (de protección, de buen trato, etc.) y, por otra parte, una vía nueva, más radical, que predica hacer de los animales sujetos de derecho, como ocurre con las personas. Es lo que reivindica, por ejemplo, la "Declaración universal de los derechos del animal" (ien singular!) de 1978, o el "Reporte sobre el régimen jurídico del animal" (no se olvide ien singular!) enviado en el 2005 al ministro de justicia por la magistrada Suzanne Antoine, partidaria de la reforma del Código Civil en este sentido (Coulon \& Nouët 2010).

Los cambios comprometen igualmente muchas disciplinas científicas. En etología, la violencia y la dominación constituían hasta hace muy poco, los grandes principios explicativos de los comportamientos animales (Lorenz 1969). Hoy esas nociones han cedido su lugar a las de cooperación y de solidaridad; por ejemplo, la "familia ideal" se encontraría entre las mangostas (Rasa 1990), y los babuinos serían "casi humanos" (Strum 1990). Paralelamente a este cambio de paradigma, se ha operado un doble movimiento. Primero un movimiento de desclasamiento del hombre; comenzado por la sociobiología que busca estudiar a los humanos como animales (human animals), por medio de la sola biología ${ }^{9}$, ese movimiento fue amplificado, siguiendo a Desmond Morris (1968), por una cierta etología menos cuidadosa del rigor metodológico que de la explotación de un jugoso filón editorial (De Waal 2006 ; Picq 2012). El segundo movimiento, corolario del primero, es un movimiento de promoción de los animales hacia posiciones filogenéticas y taxonómicas no tan alejadas de las del hombre puesto que, de ahora en adelante, los animales "pensarían" (Griffin 1988 [1984]) y tendrían "cultura"10. De hecho, los etólogos que encuentran "cultura" en los animales movilizan para dicho efecto una definición a mínima de este concepto, que los biólogos utilizan en realidad hace mucho tiempo para designar "todo lo que, en el comportamiento de un animal es adquirido en el curso de la existencia por imitación de otros miembros de la población, y no transmitido genéticamente" (Dubois 2008), definición que evidentemente está muy alejada de la de los antropólogos (Godelier 1998).

\footnotetext{
9 Edward O. Wilson (1975), que fue uno de sus principales promotores, era especialista en hormigas. Cf. también Christen (2009).

10 Marshall Thomas (1995) para los perros, (2004) para los gatos; Joulian (2000) para los chimpancés.
} 
En los EE. UU., un esfuerzo de síntesis de estas diversas movidas apareció bajo el nombre de animal studies. Estos predican una "etología para las ciencias humanas", así como una "epistemología crítica" de las maneras de pensar las relaciones hombres / animales, maneras de pensar que ellos consideran como "polucionadas por nuestra noción de lo "propio del hombre"». Uno de sus principales representantes en Francia (al menos así se reclama él), Dominique Lestel, retoma y profundiza la idea de sociedades y de sociabilidades "híbridas" cada vez que las sociedades humanas desarrollan relaciones privilegiadas, no simbióticas y no depredadoras, que implican "repartos de sentidos, de intereses y de afectos", en "dispositivos a veces muy complejos y de una gran creatividad" con al menos "otra especie animal" (es Digard el que subraya) o incluso con robots (Lestel 2006).

La última, pero no la menos importante de las intrusiones animalistas en el campo científico, ha tomado prestados los rasgos de una antropología crítica pos-estructuralista, monista e hiper-relativista. Bajo esta etiqueta, aún indecisa y provisional, yo pongo principalmente la tarea de Philippe Descola en Más allá naturaleza y cultura (2005). Recordemos que este autor coloca aquí en el mismo plano, en un mismo "sistema de distribución de propiedades" cuatro ontologías que él designa por medio de términos clásicos -naturalismo (la "ontología moderna"), animismo, analogismo y totemismo-, pero tomados en sentido nuevos, fundamentados en la semejanza o en la diferencia de las interioridades o de las fisicalidades de los "entes", seres vivos, cosas o espíritus (Ibíd.: 176). Ya dije en otra parte (Digard 2006) todas las reservas que me suscita ese "mundo plegado en cuatro" (Libération del 17 de noviembre de 2005); después de haber sufrido tanto para desembarazarnos de categorías antropológicas obsoletas ¿ahora nos tocará quebrar las sociedades y las culturas en una u otra de estas cuatro ontologías? Y por lo demás ¿por qué cuatro más bien que tres o seis? ¿Y por qué no la del "fetichismo" que, del presidente de Brosses hasta Freud, y luego Lacan, no ha dejado de atormentar al pensamiento del ser-ahí que no está ahí? En suma: dudo que esas ontologías sean aplicables, y no veo en qué constituyan un avance, pero ellas no son acá mi objetivo; la crítica que me gustaría dirigirle a Philippe Descola tiene que ver con otro aspecto, particular pero esencial, del modelo que propone; con motivo (por lo demás discutible) de que "de aquí en adelante es difícil hacer como si los no-humanos no estuvieran por todas partes en el corazón de la vida social" (Descola 2005: 15), nuestro autor decide repensar el dominio y las herramientas de la antropología "de manera que pueda incluir en su objeto mucho más que el anthropos, toda 
esa colectividad de entes ligados a él, y relegados hasta el presente en una función de entorno" (ibíd.). En el proyecto descoliano, la antropología estaría pues llamada a ser algo más que la ciencia del hombre, sería la ciencia de los "entes"... En esto, Philippe Descola no ha hecho más que seguir a Bruno Latour cuya "antropología simétrica" (2001) proponía "ampliar la gama de los actores" incluyendo allí a los "no-humanos" (2006: 93-101), idea que campea ya en muchos campus norteamericanos...

El primer riesgo engendrado por esta ambición es el de una dilución de la disciplina antropológica y de su objeto, que no tienen necesidad de esto; ¿qué le ocurriría, por ejemplo, a una entomología que pretendiera incluir a en su campo al conjunto de los artropos? El segundo riesgo es que ese brillante y erudito libro que es Más allá naturaleza y cultura anima y le aporta a pesar suyo una caución, ejecutorias, un lustre inesperado a corrientes de pensamiento que están desprovistas singularmente de ello. En efecto se puede temer que la antropología ampliada predicada por Philippe Descola suscite vocaciones de imitadores, e inspire trabajos que solo tendrían de científico el nombre, trabajos de los que no dejarán de apoderarse ecologistas extremistas -partidarios ciegos del "anti-especismo", sostenidos por algunos filósofos extraviados- para confortar y justificar sus sueños más utópicos de "nuevo contrato" o de "fusión" con la naturaleza, o aún de "liberación animal", todas exageraciones que evidentemente solo complican los problemas y alejan las soluciones.

\section{Manifestaciones y publicaciones recientes}

Las diferentes disciplinas y corrientes de pensamiento que acabamos de evocar constituyen en efecto un terreno sobre el cual no dejan de proliferar, desde hace una decena de años, coloquios y publicaciones que, al mismo tiempo que se inscriben en el campo de las ciencias del hombre y de la sociedad, tienen en común buscar borrar toda diferencia entre el hombre y los animales. Para no atiborrar inútilmente este texto, el florilegio se limitará a Francia.

Las compuertas del animalismo en antropología se abrieron en el 2000, en un número especial de Terrain titulado "Les animaux pensent-ils?», introducido por Gérard Lenclud, con contribuciones de Frédéric Joulian, Joëlle Proust, Véronique Servais, etc., del que inmediatamente publiqué una reseña alarmista y premonitoria (Digard 2000). 
Una multitud de epígonos proliferaron luego por la senda abierta por Philippe Descola y / o Dominique Lestel (la paternidad es difícil de establecer aquí pues los vástagos son irreconocibles). Entre ellos, Albert Piette, profesor de etnólogía en Amiens, luego en Nanterre, predica una "etnografía del hecho socio-animal" (2002), mientras que su alumno Marion Vicart se entrega, observando a su perra Moksha o a una hembra macaco encontrada en el bosque de Kintzheim en Alsacia, a ejercicios de "fenomenografía equitativa" $(2008,2010)$. Por su lado, Dominique Guillo publica un «ensayo de sociología interespecífica" de las "sociedades antropocaninas" (2009: 294). Sophie Houdart se preocupa, de manera más amplia, menos tosca, pero no menos equívoca, de llamar a los «non-humanos» para "repoblar las ciencias sociales» (Houdart \& Thiéry 2011). Leyendo a todos estos autores, uno no puede dejar de preguntarse si las ciencias sociales se quedaron sin rigor o sin objeto, y lo que ellas ganan al haberse transformado así en albergue de todo el mundo.

Visiblemente estas dudas no han afectado a los investigadores que recientemente se han agrupado en redes en torno a temas animalistas. La primera en fechas es, a mi conocimiento, la asociación IpRAz ("Imaginaires, pratiques, relations anthropozoologiques») fundada por Emmanuel Gouabault, de la Universidad de Ginebra, y Jérôme Michalon, de la de Saint-Étienne, donde se organizó un primer coloquio "Relations anthropo-zoologiques»" en 2008, seguido de un segundo en la Université de Genève en 2010, luego de un tercero en la Ens de Lyon, en 2011... Mientras tanto, en marzo de 2009, el diario Le Monde había consagrado sus "Rencontres philosophiques» a la cuestión de saber "Qui sont les animaux?». Se pueden encontrar descritos, en las actas de esos encuentros (Birnbaum 2010), muchos rasgos o índices de un "giro animalista" en antropología, especialmente el que se le debe a Frédéric Keck, autor por lo demás de una vasta encuesta sobre el miedo colectivo a la gripe aviar analizada como un «mito» (Keck 2010a):

Las ciencias sociales se constituyeron en el siglo XIX para responder a la pregunta: "¿Tienen las clases populares y los pueblos colonizados los mismos derechso que las élites europeas?" [...] Así mismo en la actualidad, las ciencias sociales pueden responder a la "cuestión animal": ¿tienen los animales los mismos derechos que los humanos y cómo aplicarlos en las fincas y los laboratorios? (Keck 2010b: 136-137).

Más recientemente, el 17 de enero de 2011, en la Maison européenne de las SHs de Lille, se llevó a cabo un coloquio internacional «Études animales, perspectives françaises» donde se presentaron muchas comunicaciones

11 Las actas de ese coloquio han sido publicadas en la revista Sociétés (2010, 108), editorial De Boeck de Lieja. 
sintomáticas; además de la de aquí en adelante sempiterna "Contestación del sistema cartesiano del 'animal máquina' "aquí recitada por Peter Sahlins venido expresamente de Berkeley, se escuchó a Catherine Rémy (CNRS) hablar del estudio de las "relaciones híbridas" y de la "común corporeidad" de los hombres y de los animales; a Pierre Serna (Université Paris 1) preguntarse: "L'animal est-il un citoyen comme un autre pendant la Révolution?»; a Éric Baratay (Université Lyon 3) proyectar "Écrire l'Histoire du point de vue de l'animal [...] pour voir comment ils vivent, perçoivent, ressentent les phénomènes historiques dans lesquels les hommes les entraînent», etc. Este último autor, por lo demás, acaba de desarrollar su cuestionamiento en un libro (Baratay 2012), con una erudición muy orientada, y cuyo propósito consiste en lo esencial reducir las relaciones mantenidas por los hombres y los animales en el curso de la historia a una serie ininterrumpida de malos tratos infligidos por los primeros a los segundos, tratos a tal punto exagerados ique habría sido sorprendente que los animales no los hubieran sentido, COFD! En la misma vena, aparece igualmente en ese año 2012, en Études rurales un número especial «Sociabilités animales» (n. $\left.{ }^{\circ} 189\right)$, que comporta, entre otros pedazos de valentía, una etnografía de un rebaño de vacas que vale su peso en heno; conjunto confeccionado minuciosamente por Florent Kohler, de la université de Tours, uno de los nuevos chantres de la "antropología de los no-humanos"...

Finalmente, cómo no evocar también -así estemos fatigando al lectoresos coloquios repetitivos cuyo único objetivo parece ser ocupar el terreno reuniéndose siempre las mismas personas entre las cuales, al abrigo de contradictores, circula en bucle la "buena palabra": del 2 al 9 de julio de 2010 en Cerisy sobre "Ce que nous savons des animaux", insistiendo (precisaba el programa) en la "multiplicidad" de ese saber, intención exhibida inmediatamente contradicha por la lista de los participantes, los mismos con las mismas y solo ellos: Vinciane Despret, Raphaël Larrère, Florence Burgat, Georges Chapouthier, Isabelle Stengers, etc.; en octubre de 2011 en Rennes, luego de Abou Dhabi, Cape Town, Delhi, Londres, New York, Oslo, San Francisco, Newcastle (Australie, en 2009), Sydney (en 2010) y antes en Utrecht (en 2012), un enésimo coloquio "Minding Animals» con, una vez más y siempre por los franceses, Florence Burgat, Élisabeth Hardouin-Fugier, Jean-Baptiste Jeangène Vilmer...

Y como si la extensión del campo de la antropología por fuera de los límites de lo razonable no fuera suficiente, estos pioneros de la antropología animalista no retroceden ante ningun exceso interpretativo. La forma más 
benigna de esta exageración es el abuso -por no decir la impostura-metafórico. Pongamos un primer ejemplo: del 12 de septiembre de 2007 al 20 de enero de 2008 tuvo lugar en el Parc de la Villette de París una exposición "Bêtes et hommes» cuyo comisario fue Vinciane Despret; a una pregunta del periodista Bertrand Le Gendre sobre la presencia de nutrias y de buitres en jaulas, a la entrada de la exposición, Vinciane Despret responde que esos animales son "nuetros invitados [...] para testimoniar a nombre de los otros animales" ( $L e$ Monde del 7 de octubre de 2007). Un segundo ejemplo es sacado de la obra Humains, non-humains. Comment repeupler les sciences sociales, ya citada (Houdart \& Thiéry, eds 2011) y a la que -dicho sea de paso- Le Monde des Livres del 4 de febrero de 2011 le consagró dos páginas tituladas "Darle un lugar a los no-humanos"; al estudiar la utilización de moluscos bivalvos del género Corbicula como "centinelas biológicos" del estado de los cursos de agua dulce, dos de los colaboradores del libro escriben: "Con el acuerdo de los otros organismos vivientes habilitados por los científicos para hablar por los ríos, los Corbicula podrían ciertamente también sugerirnos otras maneras de hacer [...] el entorno" (Gramaglia \& Sampaio da Silva 2011: 232). Leyendo estas líneas uno no puede dejar de imaginarse a Éric Baratay indignándose: ¿se les ha pedido su opinión a esos buitres, a esas nutrias, a esos moluscos?

La forma maligna de la exageración es el delirio interpretativo, que afortunadamente la mayor parte del tiempo es a tal punto caricaturesco, que produce más risa que credibilidad. Pongamos dos ejemplos. Habiendo observado el comportamiento de jóvenes chimpancés de los dos sexos, que manipulaban bastones, dos investigadores en etología de Harvard concluyen que los machos se sirven de ellos como de armas, y las hembras, como muñecas... (Kahlenberg \& Wrangham 2010). Pero ciertamente es el segundo ejemplo -sacado de la tesis defendida por Cédric Sueur en 2008 en Estrasburgo y titulada Sobre la democracia participativa entre los monos. Estudio comparativo de la influencia de las relaciones sobre la organización de los desplazamientos colectivos en dos especies de macacos- el que arrebata todos los laureles ${ }^{12}$. ¿De qué se trata? El autor observó el comportamiento de una tropa de macacos que estaban buscando alimento: el grupo duda entre un árbol frutal y una charca de agua, luego se dividen entre las dos direcciones, y finalmente se reagrupan, siendo el minoritario el que busca al mayoritario. Conclusión del autor: son los monos, y no los humanos, los que inventaron la democracia (aquí confundida icon el gregarismo!).

12 La mencionada tesis fue por lo demás coronada con el premio a la mejor tesis del periódido Le Monde en la categoría... i"ciencias exactas"! 
El sorprendente florilegio que acabamos de recorrer confirma (si es que había necesidad de ello) el diagnóstico más pesimista; sí, un giro animalista está ocurriendo, se está produciendo en antropología. Como van las cosas no me sorprendería que un día de estos no lejano algún investigador "innovador" (como se estila decir ahora) no trate de convencernos de que no se nace humano o animal sino que uno se vuelve, y que hay que ser horriblemente "esencialista" -injuria suprema en nuestros días- para pensar de otra manera... Peor aún, esta evolución confiere verosimilitud al escenario-catástrofe montado por Philippe Muray, con sus dosis de humor (negro): "La nueva civilización ["hiperfestiva"], para deshacerse de la humanidad, se dedica activamente a [...] zoologizarla" (Muray 2010 [2000]: 68). Y más adelante:

Cuando esta acción positiva a favor de la igualdad de oportunidades para el mundo animal haya dado sus frutos, y que las anomalías que hasta entonces parecían naturales o fatales se hayan vuelto inadmisibles, entonces todas las capitales del mundo organizarán desfiles monstruosos, especies de Zoo Prides o de Animal Parades [...]. Y así se encontrará celebrada, en una especie de Noche del 4 de Agosto < de 1789, llamada noche de la locura, pues la Asamblea francesa acordó la supresión del feudalismo > planetario, la abolición del especismo en el que se resumía desde hacía siglos el crimen de distinguir aún un mundo humano de un mundo animal. Evidentemente que esta abolición dará comienzo a la cacería de los últimos animófobos, y por tanto la puesta en funcionamiento de nuevos instrumentos de derecho penal [...] Así se llenará igualmente, y con aplausos unánimes, un nuevo vacío jurídico. (Ibíd.: 474-475)

Pero ya la realidad superó la ficción, al menos en horror; desde mayo de 2011, en los EE. UU., condenados a muerte son ejecutados con inyección de anestesiantes para animales (Le Monde del 19 y del 21 de mayo de 2011)...

\section{Balance y perspectivas}

\section{No hay historia autónoma de las ideas}

Zoomanía popular, animalitarismo militante y animalismo intelectual están conectados, se recubren en parte y se nutren los unos a los otros. Mientras que la zoomanía ha suscitado un "políticamente correcto" que participa y genera misantropía ${ }^{13}$, las tesis animalistas, por su lado, se muestran portadoras de los gérmenes de un nuevo oscurantismo; alimentan la denegación de lo que es propio del hombre, denegación que solo quiere ver la continuidad biológica con las otras especies, y que permanece ciega al hiato en las obras, testigo

\footnotetext{
13 «Entre más conozco a los hombres, más amo a los animales», lo he escuchado por doquier en mis investigaciones en Francia (Digard 2005 [1999]: 194).
} 
de un salto evolutivo, cualitativo tanto como cuantitativo, en un proceso genético y neurológico de hominización que ha durado más de iveinticinco millones de años! Las tesis animalistas participan en el descrédito de la ciencia al abundar en el sentido de los que la presentan como un discurso o una "ontología" más entre las otras. Por una especie de proceso perverso, las ciencias del hombre y de la sociedad, con el motivo justo de que todo no es sino materia, dan particular importancia a este rebajamiento; interesados más en las representaciones que en las prácticas y / o confundiéndo las unas con las otras, dejándose caer por sus pendientes pansimbolistas y metaforistas que permiten decir todo y su contrario -siendo el parangón de esta tendencia iEdouardo Viveiros de Castro (2009)!- ahondan a su amaño la distancia que los separa de las ciencias físicas y biológicas, no sin suscitar de parte de estas últimas burlas o menosprecio, como lo testimonian calificativos como "ciencias blandas", Imposturas intelectuales (Sokal \& Bricmont 1997) y, últimamente, bullshitology (Frankfurt 2005; cfr. también Elster 2010). Si existe un claro giro animalista en antropología, no hay ninguna duda de que él es también un giro oscurantista.

Para no continuar en este tono pesimista, corriendo el riesgo de agravar mi caso de un humanismo que expira, y de vestigios de un positivismo trasnochado, desearía terminar tratando de presentar a pesar de todo algunas perspectivas.

\section{Es posible una síntesis}

El paradigma animalista, la superación de la oposición naturaleza / cultura, el Naturalistic Turn de Brian Leiter (2004), etc., son presentados como uno de los grandes giros intelectuales y científicos de estos últimos veinte años, tanto por los que se inscriben en esta evolución (Dortier 2010) como por los que la critican (Wolff 2010). Tanto los unos como los otros describen la evolución actual como el reemplazo de un paradigma, el del "hombre estructural", por un nuevo paradigma, el del "hombre neuronal"...

¿Pero no habrá otra manera de encarar las cosas? ¿No serán los dos enfoques complementarios, indisociables incluso?

Me parece que sería científicamente más productivo enfrentar una continuidad y / o una colaboración, más bien que una oposición, entre ciencias del hombre y de la sociedad, y ciencias de la vida, entre antropología social y cultural y antropología física y biológica. Pienso especialmente aquí en los trabajos de neurobiólogos tales como los de Lionel Naccache sobre las 
diferencias entre información y conocimiento (2010) o de Antonio Damasio, sobre el cerebro humano como órgano social que se construye en contacto con otros cerebros (2010); leyéndolos uno se pone a pensar que nuestras "humanidades" pronto no van a pesar mucho frente a los descubrimientos de las neurociencias... ¿No es en un marco unificado donde debería ser reconsiderada la distinción entre "naturaleza" -lo que está "dado"- y "cultura" -lo que se "cultiva"- puesto que es verdad que la cultura hace parte de la naturaleza del hombre?

\section{Por un enfoque positivo de los hechos sociales y culturales}

Hace un instante zaherí la propensión de los antropólogos a dejarse llevar por algunas de sus pendientes esotéricas que permiten decir todo y su contrario, y cavar así a su amaño la fosa que los separa de las "ciencias duras"... iCuánto más habrá que meditar los defectos y las insuficiencias que Claude LéviStrauss imputa a la formación filosófica en el capítulo "Cómo se llega a ser etnógrafo" de Tristes trópicos! Más de medio siglo después, Vincent Debaene regresa a la carga evocando al respecto "una excepción francesa" (2010: 86); mientras que los antropólogos anglosajones se concentran "en las reglas de sucesión, la economía y el régimen de tierras", sus homólogos franceses prefieren asomarse "al arte y a la mitología" y "hacen películas"; los primeros escriben "sobriamente de manera analítica", los segundos "líricamente, de manera expresiva"; los primeros están dotados de "pragmatismo", los segundos de un "temperamento especulativo y filosófico" (Ibíd.). Sea lo que fuere de estas apreciaciones un tanto maniqueas (y excesivamente complacientes con respecto a nuestros colegas anglosajones), es preciso reconocer que los antropólogos franceses, con alguna excepción, han mostrado hasta el presenta más agilidad intelectual que verdadero rigor científico.

Además de su deseable aproximación a la biología ya evocada, me parece que la antropología, si quiere conservar su sitio entre las ciencias, tendría interés en buscar de urgencia las vías de un enfoque positivo de los hechos sociales y culturales; entiendo por esto: una aproximación en la que la interpretación de los hechos estuviera estrictamente enmarcada y controlada. No es cuestión de exponer aquí un tal programa. Sus principales elementos son, mientras tanto, bien conocidos y será suficiente con ponerlos en funcionamiento con un máximo de rigor. Me contentaré aquí con recordar cuatro:

1) el establecimiento riguroso y la descripción precisa y tan objetiva como sea posible, de un corpus de hechos constituye la base de la etnología; 
a veces esta es también su fin pues la descripción minuciosa del cómo muy frecuentemente es suficiente para hacer surgir el por qué.

2) Una distinción se impone entre las prácticas, que son realidades observables, y las representaciones, que son operaciones del pensamiento, transmisibles únicamente por el discurso. Por ejemplo, la materialidad de los hechos muestra que las sociedades que practican la caza, aunque le presten una humanidad a los animales salvajes, matan y se comen a estos ejerciendo sobre ellos acciones que no difieren de las que ejercen en otras partes otros cazadores; solo difieren por las representaciones que los unos y los otros se hacen de sus acciones respectivas. Se habrá comprendido que este principio se opone a la concepción constructivista, para la que no existen otras realidades que las representaciones que de ellas se hacen los actores sociales. Ciertas prácticas y representaciones están ligadas. Sin embargo el acento que predico poner en las prácticas debe comprenderse (aquí parafraseo a Jean-Pierre Changeux) no "como una toma de posición ideológica ["materialista", según una sospecha que a menudo pesa sobre esta orientación metodológica], sino simplemente como la hipótesis de trabajo más razonable", por ser la más positiva, en el sentido que es la que menos sitio le deja a los azares de la interpretación. Por lo demás, Changeux ilustraba con una cita de John Stuart Mill: "si ser materialista es buscar las condiciones materiales de las operaciones mentales, [entonces] todas las teorías del espíritu deben ser materialistas... o serán insuficientes" (Changeux 1983: 363). En el fondo, es por un regreso al materialismo -a este materialismo, metodológico-por el que abogo en la actualidad.

3) el conocimiento de las culturas no podría limitarse a la visión que de ellas tiene sus detentadores; en otros términos (que tomo prestado de un chascarrillo de Christian Bromberger): no es suficiente con tender un micrófono para hacer etnografía (ver la oposición emic/etic). El etnólogo debe someter los discursos indígenas a la crítica -¿quién habla?, ¿de qué habla?, ¿a quién le habla?, ¿en qué contexto?- de la misma manera que el historiador procede a la crítica de sus fuentes (archivos, crónicas, inventarios...). Los discursos indígenas no podrían pues ser colocados en el mismo plano que el proceder científico que supone -sin ofender al deconstruccionismo postmoderno- métodos propios de investigación, de crítica, de comparación, de verificación de hechos, de evaluación de métodos, etc. 
4) Y finalmente, la ciencia, y a fortiori la antropología, no son atributos de Occidente; ellas tienen vocación universal -al menos deberíamos esforzarnos en darles esta dimensión-y si una cierta dosis de relativismo es necesaria para la comprensión de la diversidad cultural que incumbe a la etnología, me parece que el relativismo radical no contribuye en nada a hacer progresar el conocimiento de la identidad y de la unidad de la especie humana, que constituye a mi manera de ver el corazón del proyecto antropológico.

Yo espero que se me perdonen estas simplificaciones. De todas formas, incluso si el aire del tiempo parece hoy mostrarme como equivocado, probablemente tendrá razón mañana; el animalismo terminará por retroceder ante las evidencias y -es menester desear que no nos demos cuenta de esto demasiado tarde- la antropología será científica..., o desaparecerá.

\section{Bibliografía}

Adams, Carol J., 1995. Neither Man nor Beast. Feminism and the Defense of Animals. New York, Continuum.

Agulhon, Maurice, 1981. " Le sang des bêtes : le problème de la protection des animaux en France au xIx ${ }^{\mathrm{e}}$ siècle ", Romantisme. Revue des études romantiques 31 : 81-110 [www.persee.fr/web/revues/home/prescript/ article/roman_0048-8593_ 1981 num_11_31_4475].

Balandier, Georges, 2005. Le Grand dérangement. Paris, Presses universitaires de France.

Baratay, Éric, 2012. Le Point de vue de l'animal. Une autre vision de l'histoire. Paris, Le Seuil.

Bauman, Zygmunt, 2006. La Vida líquida. Barcelona: Paidós, 2010.

Birnbaum, Jean, ed., 2010. Qui sont les animaux? Paris, Gallimard.

Bourdon, Jean-Paul, 2003. "Recherche agronomique et bien-être des animaux d'élevage: histoire d'une demande sociale», Histoire et sociétés rurales 19: 221-239.

Burgat, Florence, 1997ª Animal mon prochain. Paris, Odile Jacob.

Burgat, Florence, 1997b. La Protection de l'animal. Paris, Presses universitaires de France.

Burgat, Florence, con la colab. de Robert Dantzer, 2001. Les Animaux d'élevage ont-ils droit au bien-être? Paris, Institut national de la recherche agronomique.

Chaix, Louis \& Patrice Méniel, 2001 [1996]. Archéozoologie. Les animaux et l'archéologie. Paris, Errance.

Changeux, Jean-Pierre, 1983. El hombre neuronal. Madrid: Espasa-Calpe, 1984.

Chapouthier, Georges, 1990. Au Bon vouloir de l'homme, l'animal. Paris, Denoël. 
Chartrand, Martin \& Jean Duhaime, 2002. "L'homme et l'animal: sélection bibliographique ", Théologiques 10 (1): 179-205.

Christen, Yves, 2009. L'Animal est-il une personne? Paris, Flammarion.

Cottingham, John, 2009. Cartesian Reflections. Essays on Descartes's Philosophy. Oxford-New York, Oxford University Press.

Coulon, Jean-Marie \& Jean-Claude Nouët, 2010. Les Droits de l'animal. Paris, Dalloz.

Dalsuet, Anne, 2010. Philosophie et écologie. Paris, Gallimard Éducation.

Damasio, Antonio R., 2010. L'Autre moi-même. Les nouvelles cartes du cerveau, de la conscience et des émotions. Traduit de l'américain par Jean-Luc Fidel. Paris, Odile Jacob.

Debaene, Vincent, 2010. L'Adieu au voyage. L'ethnologie française entre science et littérature. Paris, Gallimard.

Descola, Philippe, 2005. Más allá naturaleza y cultura (tr. Paláu, Medellín, abril de 2010 - junio de 2011).

Waal, Franz de, 2006. El mono que llevamos dentro. Barcelona: Tusquets, 2007.

Digard, Jean-Pierre, 2000. "Compte rendu de Terrain, 2000, 34: Les animaux pensent-ils?", in Études rurales 153-154: 234-237.

Digard, Jean-Pierre, 2005 [1999]. Les Français et leurs animaux. Ethnologie d'un phénomène de société. Paris, Hachette Littératures ("Pluriel»).

Digard, Jean-Pierre, 2006. «Canards sauvages ou enfants du Bon Dieu? Représentation du réel et réalité des représentations», L’Homme 177-178: 413-428.

Digard, Jean-Pierre, 2007 [2004]. Une histoire du cheval. Art, techniques, société. Arles, Actes Sud.

Digard, Jean-Pierre, 2009a [1990]. L'Homme et les animaux domestiques. Anthropologie d'une passion. Paris, Fayard.

Digard, Jean-Pierre, 2009b. "Raisons et déraisons des revendications animalitaires: essai de lecture anthropologique et politique», Pouvoirs. Revue française d'études constitutionnelles et politiques 131: 97-111.

Digard, Jean-Pierre, 2010. "Propositions pour un avenir de l'ethnozootechnie», Ethnozootechnie 89: 63-70.

Dortier, Jean-François, 2008. "Mon chien est-il libre?», Sciences humaines. Les grands dossiers 10: Les grandes questions de la philosophie: 8-10.

Dortier, Jean-François, 2010. "L'animal humanisé et l'humain naturalisé», Sciences humaines 222 [n ${ }^{\circ}$ spécial anniversaire: Vingt ans d'idées. Le basculement]: 10-13.

Dubois, Alain, 2008«La notion de pollution biotique: pollutions faunistique, floristique, génétique et culturelle», Bulletin de la Société zoologique de France 133 (4): 357-382.

Eibl, Florence, 2010. L'Homme, un animal comme les autres? Paris, Edifa-Mame. 
Elster, Jon, 2010. "Obscurantisme dur et obscurantisme mou dans les sciences humaines et sociales", Diogène 229-230: 231-247.

Équipe Écologie et anthropologie des sociétés pastorales, ed., 1979. Pastoral Production and Society / Production pastorale et société. Cambridge, Cambridge University Press / Paris, Éd. de la Msh.

Estes, James A. et al., 2011. "Trophic Downgrading of Planet Earth», Science 333 (6040): 301-306.

Ferry, Luc, 1992. El Nuevo orden ecológico. El árbol, el animal y el hombre. Barcelona: Tusquets, 1994.

Fontenay, Élisabeth de, 1998. Le Silence des bêtes. La philosophie à l'épreuve de l'animalité. Paris, Fayard.

Frankfurt, Harry G., 2005. On Bullshit. Princeton, Princeton University Press.

Godelier, Maurice, 1998. "Quelles cultures pour quels primates, définition faible ou définition forte de la culture?», in Albert Ducros, Jacqueline Ducros \& Frédéric Joulian, eds, La Culture est-elle naturelle ? Histoire, épistémologie et applications récentes du concept de culture. Paris, Errance: 217-222.

Gramaglia, Christelle \& Delaine Sampaio da Silva, 2011. "Des mollusques pour "faire parler" les rivières», in Sophie Houdart \& Olivier Thiéry, eds, Humains, non-humains...: 221-233.

Griffin, Donald R., [1984]. Pensamiento de los animales. Madrid: Ariel, 1986.

Guillo, Dominique, 2009 Des Chiens et des humains. Paris, Le Pommier.

Hemingway, Ernest, 1938 [1932]. Muerte en la tarde. http://librospdf.gratis/libro-muerte-en-la-tarde/HBCxHO8V9ZwyHBMYct7ycO8jcOcZ/

Houdart, Sophie \& Olivier Thiéry, eds, 2011. Humains, non-humains. Comment repeupler les sciences sociales. Paris, La Découverte.

Jeangène Vilmer, Jean-Baptiste, 2008. Éthique animale. Préf. de Peter Singer. Paris, Presses universitaires de France.

Joulian, Frédéric, 2000. "Techniques du corps et traditions chimpanzières», Terrain 34: Les animaux pensent-ils?: 37-54 [http ://terrain.revues.org/951].

Kahlenberg, Sonia M. \& Richard W. Wrangham, 2010. "Sex Differences in Chimpanzees' Use of Sticks as Play Objects Resemble Those of Children ", Current Biology 24 : 1067-1068 [http ://download.cell.com/current-biology/ pdf/PIIS0960982210014491. pdf ?intermediate $=$ true].

Keck, Frédéric, 2010a. Un Monde grippé. Paris, Flammarion.

Keck, Frédéric, 2010b. "Les maladies animales révèlent une solidarité vitale ", in Jean Birnbaum, ed., Qui sont les animaux ?...: 127-137.

Larrère, Catherine \& Raphaël Larrère, 1997 " Le contrat domestique ", Le Courrier de l'environnement de l'Inra 30: 5-17 [http ://www.inra.fr/dpenv/larrec30.htm]. 
Latour, Bruno, 1993. Nunca hemos sido modernos. Ensayo de antropología simétrica. Madrid: Debate.

Latour, Bruno, 2006. Changer de société, refaire de la sociologie. Paris, La Découverte.

Leiter, Brian, ed., 2004. The Future of Philosophy. Oxford, Clarendon Press / New York, Oxford University Press.

Lestel, Dominique, 2006. "Ethology and Ethnology : The Coming Synthesis. A General Introduction", Social Science Information 45: 147-153 [http ://ssi.sagepub.com/ content/45/2/147.full.pdf+html].

Lévi-Strauss, Claude, 1955. Tristes Trópicos. Buenos Aires: Eudeba.

Lorenz, Konrad, 1969. La agresión, una historia natural del mal. México: Siglo XXI, 1972.

Lyotard, Jean-François, 1979. La Condición post-moderne. Reporte sobre el saber. Paris, Minuit.

Marshall Thomas, Elizabeth, 1995. La Vie secrète des chiens. Une anthropologue en pays canin. Paris, Robert Laffont.

Marshall Thomas, Elizabeth, 2004. Les Chats et leur culture. Paris, Robert Laffont.

Meyer, Jean-Marie \& Patrice de Plunkett, 2008. Nous sommes des animaux, mais on n'est pas des bêtes. Libres propos d'un philosophe sur les chiens, les chats, les singes, les loups, les ours, les chevaux, les baleines, les tigres et les hommes: entretiens. Paris, Presses de la Renaissance.

Morris, Desmond, 1968. El mono desnudo. http://www.astroscu.unam.mx/ angel/tsb/ Desmond-Morris-El-Mono-Desnudo.pdf

Muray, Philippe, 2010 [2000]. Après l'Histoire. Paris, Gallimard («Tel» 348).

Naccache, Lionel, 2010 Perdons-nous connaissance? De la mythologie à la neurologie. Paris, Odile Jacob.

Pelosse, Vincent, 1981-1982. «Imaginaire social et protection de l'animal : des amis des bêtes de l'an X au législateur de 1850», L'Homme 21 (4) : 5-33 et 22 (1) : 33-51.

Picard, Michel, Richard H. Porter, \& Jean-Pierre Signoret, eds, 1994. Comportement et adaptation des animaux domestiques aux contraintes de l'élevage. Bases techniques du bien-être animal. Paris, Institut national de la recherche agronomique (" Un point sur ").

Picq, Pascal, 2012. L'Homme est-il un grand singe politique? Essai de primatologie politique et de pataphysique. Paris, Odile Jacob.

Pierre, Éric, 1997. "La zoophilie dans ses rapports à la philanthropie, en France, au xix ${ }^{\mathrm{e}}$ siècle», Cahiers d'histoire 42 (3-4): 655-675. Piette, Albert, 2002 " Entre l'homme et le chien: pour une ethnographie du fait socio-animal ", Socio-Anthropologie 11 : Attirances [http ://socio-anthropologie.revues.org/index141.html\#quotation].

Porcher, Jocelyne, 2002. Éleveurs et animaux, réinventer le lien. Paris, Presses universitaires de France - Le Monde. 
Porcher, Jocelyne, 2004 Bien-être animal et travail en élevage. Textes à l'appui. Dijon, Éducagri - INRA Éd.

Porcher, Jocelyne, 2011. Vivre avec les animaux. Une utopie pour le xxie siècle. Paris, La Découverte ("Textes à l'appui. Bibliothèque du Mauss»).

Pujol, Raymond \& Geneviève Carbone, 1990. "L'homme et l'animal ", in Jean Poirier, ed., Histoire des mœurs, 1. Les Coordonnées de l'homme et la culture matérielle. Paris, Gallimard (" Encyclopédie de la Pléiade » 47) : 1307-1388.

Rasa, Anne, 1990. La Famille idéale. Vie sociale des mangoustes. Trad. de l'allemand par Jeanne Etoré. Paris, Odile Jacob.

Rufin, Jean-Claude, 2007. Le Parfum d'Adam. Paris, Flammarion.

Singer, Peter, 1993 [1975]. La Libération animale. Trad. de l'anglais par Louise Rousselle. Paris, Grasset.

Sokal, Alan \& Jean Bricmont, 1997. Impostures intellectuelles. Paris, Odile Jacob.

Strum, Shirley C., 1990. Presque humain. Voyage chez les Babouins. Trad. de l'anglais par François Simon-Duneau. Paris, Eshel.

Sueur, Cédric, 2008. De la Démocratie participative chez les singes. Étude comparative de l'influence des relations sur l'organisation des déplacements collectifs chez deux espèces de macaques. Strasbourg, Université Louis-Pasteur, thèse de doctorat [résumé par l'auteur dans Le Monde du 15 octobre 2009].

Turina, Isacco, 2010. "Éthique et engagement dans un groupe antispéciste», L'Année sociologique 60 (1): 163-187.

Vicart, Marion, 2008. "Regards croisés entre l'animal et l'homme : petit exercice de phénoménographie équitable», Ethnographiques.org 17 [http ://www.ethnographiques.org/2008/Vicart].

Vicart, Marion, 2010. «Où est le chien?: à la découverte de la phénoménographie équitable», Sociétés 108 : 89-98.

Viveiros de Castro, Eduardo, 2009. Métaphysiques cannibales. Lignes d'anthropologie post-structurale. Paris, Presses universitaires de France; Metafísicas caníbales (Viveiros de Castro.pdf ed. Katz).

Wilson, Edward O., 1975. Sociobiology. The New Synthesis. Cambridge, Belknap Press of Harvard University Press.

Wolff, Francis, 2010. Notre Humanité. D'Aristote aux neurosciences. Paris, Fayard; Nuestra humanidad. De Aristóteles a las neurociencias (tr. Paláu, Medellín, enero - noviembre de 2016 / enero de 2017). 